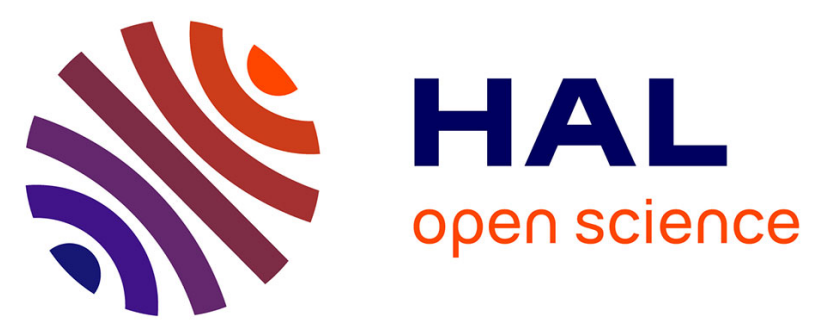

\title{
Experimental determination of the equivalent-layer shear stiffness of CLT through four-point bending of sandwich beams
}

Olivier Perret, Arthur Lebée, Cyril Douthe, Karam Sab

\section{To cite this version:}

Olivier Perret, Arthur Lebée, Cyril Douthe, Karam Sab. Experimental determination of the equivalent-layer shear stiffness of CLT through four-point bending of sandwich beams. Construction and Building Materials, 2018, 186, pp.1132-1143. 10.1016/j.conbuildmat.2018.07.102 . hal-01978755

HAL Id: hal-01978755

https://hal-enpc.archives-ouvertes.fr/hal-01978755

Submitted on 11 Jan 2019

HAL is a multi-disciplinary open access archive for the deposit and dissemination of scientific research documents, whether they are published or not. The documents may come from teaching and research institutions in France or abroad, or from public or private research centers.
L'archive ouverte pluridisciplinaire HAL, est destinée au dépôt et à la diffusion de documents scientifiques de niveau recherche, publiés ou non, émanant des établissements d'enseignement et de recherche français ou étrangers, des laboratoires publics ou privés. 


\title{
Experimental determination of the equivalent-layer shear stiffness of CLT through four-point bending of sandwich beams
}

\author{
Olivier Perret ${ }^{\mathrm{a}}$, Arthur Lebée ${ }^{\mathrm{a}, *}$, Cyril Douthe ${ }^{\mathrm{a}}$, Karam Sab \\ ${ }^{a}$ Laboratoire Navier, UMR 8205, École des Ponts ParisTech, IFSTTAR, CNRS, Université Paris-Est \\ 6-8 Avenue Blaise Pascal, Cité Descartes, Champs-sur-Marne F- 77455 Marne-la-Vallée
}

\begin{abstract}
In this paper, a new methodology for the experimental determination of the CLT equivalent cross-layer shear elastic modulus is suggested using a wooden core sandwich beam with Carbon Fiber Reinforced Polymer skins under four-point bending. The stiffness contrast between the wooden layer and the CFRP skins ensures that the bending stiffness of the sandwich beam is mostly driven by the CFRP skins and the shear force stiffness of the beam is mostly driven by the shear modulus of the wooden core. Several measurements for the determination of the bending stiffness of the sandwich beam are investigated. Particularly, it is shown that the suggested measurement of the bending stiffness from rotation at beam ends presents more reliable results than common measurements of curvature. Then the results of a preliminary experimental study are presented using this set-up and promising results are obtained: the equivalent cross-layer shear modulus is measured at $124 \mathrm{MPa}$ which lies well within literature.
\end{abstract}

Keywords: Cross Laminated Timber, Rolling-shear modulus, Equivalent cross-layer behavior, Sandwich beam, Four-point bending

\section{Introduction}

Cross-Laminated-Timber (CLT) is a wooden product made of several lumber layers stacked crosswise and glued on their wide faces. CLT panels are classically used in 5 walls, floors and roofs as load carrying plate elements. Because of their low self-weight, their quick and easy assembly and their low environmental impact, CLT panels have gained in popularity during the last few years in Northern America and in Western Europe. Several timber 10 buildings made partly or entirely of CLT were built such as the Stadthaus building at Murray Grove in London [1], the Treet in central Bergen [2] and many other projects are in progress such as the Ho-Ho building in Vienna [3] and the student residence Brock Commons in Vancouver at the University of British Columbia [4].

Nevertheless, timber is a highly anisotropic material. The shear modulus between radial and tangential directions of softwood species, also called rolling shear, is two hundred times smaller than the Young modulus in

${ }^{*}$ Corresponding author

Email addresses: olivier . perret@enpc . fr (Olivier Perret), arthur. lebee@enpc . fr (Arthur Lebée),

cyril.douthe@ifsttar.fr (Cyril Douthe), karam.sab@enpc.fr (Karam Sab) the rolling shear significantly contributes to the global behavior of the CLT panel. Several recommendations are currently being developed to include these effects. The $\gamma$-method recalled in Eurocode 5 [5] was adapted to CLT [6] considering cross layers as mechanical joints between longitudinal layers having a stiffness related to the rolling shear modulus. The shear analogy method [7] models the CLT beam as two virtual beams: an Euler beam without shear deformations and a Timoshenko beam including shear stiffness of each layer. These simplified approaches may not always be sufficient for predicting the mechanical behavior of CLT and some advanced modelling are often required $[8,9,10,11]$. Finally, in the CLT-designer software ${ }^{\circledR}$, Thiel and Schickhofer [12] suggest to use Timoshenko beam theory and derived the shear stiffness of the CLT beam from the Jouravskii method. In all these approaches a reasonable estimate of the equivalent layer shear modulus is of importance.

Numerous approaches have been suggested to measure stress concentrations or because of indirect measurement of the shear modulus. Moreover, a difference was observed between the local rolling shear modulus at ring scale, mea- 
sured at $50 \mathrm{MPa}$ approximately for softwood species and

ord scale which may be significantly larger $[14,15,16]$. Indeed, at ring scale, wood elastic behavior may be modeled as orthotropic with three 85 main directions: the longitudinal direction $L$ corresponding to wood fibers orientation, the radial and tangential directions $R$ and $T$ (Figure 1). At board scale, the rotation of the material orthotropic coordinate system $(O, L, R, T)$ generates an additional heterogeneity. Hence, the refer- 90 ence frame of the board is defined as $(O, L, C, Z)$ where $C$ and $Z$ stand for cross and normal directions of the board (Figure 1). From these considerations, it appears that the relevant definition of rolling shear modulus for engineering predictions of CLT plate behavior is an averaged property 95 of the actual heterogeneity in a CLT layer which itself is made of the assembly of glued or unglued boards.

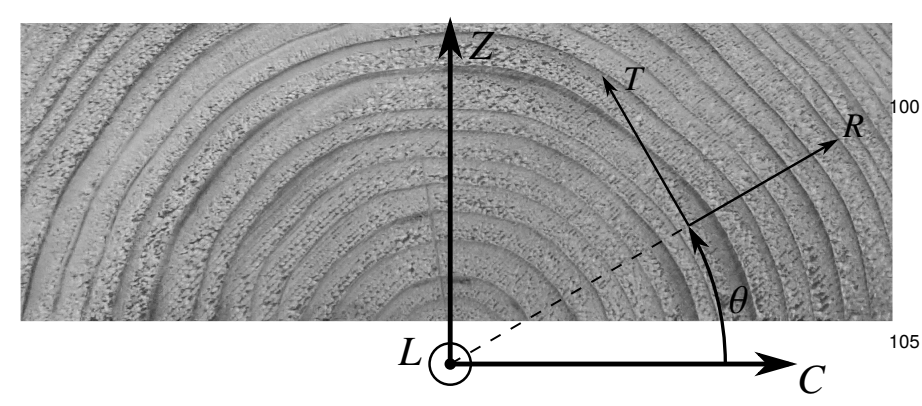

Figure 1: Local and global orientations in a board

In the present paper, we suggest a new experimental approach using the four-point bending test on a sand-110 wich beam made of a wooden core between two Carbon Fiber Reinforced Polymers (CFRP) skins. In this setup, the cross-layer of a CLT is isolated from other layers and mostly contributes to the global shear behavior of the sandwich beam. It ensures a stress state close to the actual one ${ }^{115}$ in CLT and a proper and relevant measurement of the equivalent layer shear modulus which is the relevant data for engineering applications. This equivalent shear mod-

70 ulus is denoted $G_{C Z}$ following the reference frame of the board.

In Sections 1.1 to 1.3 several experimental studies on the shear behavior of timber are reported and classified according to the specimen scale: from the ring scale to the beam scale. After that, in Section 1.4, the suggested methodology is briefly introduced. In Section 2 , the valid- ${ }^{-125}$ ity of the sandwich beam model under four-point bending is investigated for specimen with a wooden core and CFRP skins. A measurement of the apparent bending stiffness from the rotation at supports is suggested and compared to already existing methods. Then, the feasibility and the ${ }^{130}$ relevance of the methodology is validated experimentally: the protocol is shown in Section 3 and main results on Norway Spruce specimen are presented in Section 4.

\subsection{Tests at the ring scale}

Numerous studies have been published on the local rolling shear modulus of elasticity $G_{R T}$ of timber using many different tests which were extensively reviewed and analyzed by Dahl and Malo [17]. In these tests, a particular attention is always paid to the relative size of specimens compared to the radius of curvature of annual rings in order to preserve a uniform orientation.

The first methodology consists in compression tests on small timber blocks with geometries and loading configurations leading to a local shear state in timber. Several of them are listed by Kollman and Côté [18]. The notched shear block test suggested by the American Society for Testing and Materials (ASTM) [19] consists in the compression of a small cubic block with notches (Figure 2). This test has been extensively used to measure shear strength of timber, some of which are reported in [18]. Nevertheless it has been criticized by many authors [17, 20, 21] because of three main drawbacks: it introduces high stress concentration caused by the notch, an additional bending moment is caused by the load eccentricity and the non-uniform stress distribution over the failure plane yields inaccurate strength results. Moses and Prion [22] captured these effects by a finite elements model and observed that they lead to an underestimation of the shear strength by a ratio of 1.7 approximately. A comparable test method called short beam tests consists in a beam with a very small span to depth ratio uniformly loaded. Dahl and Malo [17] observed improper failure due to additional bending moment and to impure stress state.

Another configuration is called the Iosipescu shear test [24]. A beam with $90^{\circ}$ notches at top and bottom of the central section is loaded such that the central section is under pure shear stress. Using this method, Dumail et al. [25] measured an average rolling shear modulus of $57.7 \mathrm{MPa}$ on specimen made of Norway Spruce where the variations of ring orientation were negligible. Nevertheless, because of the bending moment close to the central section, the shear failure can be affected by improper failure particularly in the radial-tangential plane.

Using a comparable mechanical principle, the Arcan shear test [26] consists in loading specimens with a butterfly shape, which is intended to generate pure shear failure at the center section (Figure 2). Dahl and Malo [17] used this test in six different configurations to measure the shear modulus in the three orthotropic directions and evaluated an averaged rolling shear modulus of Norway Spruce equal 

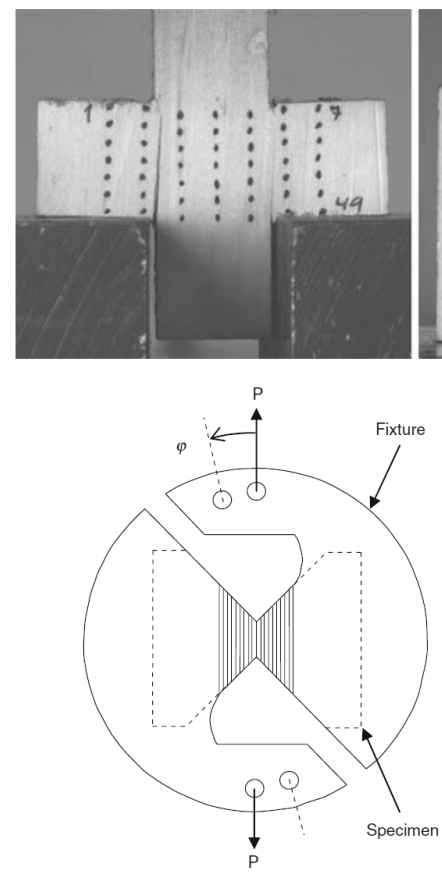

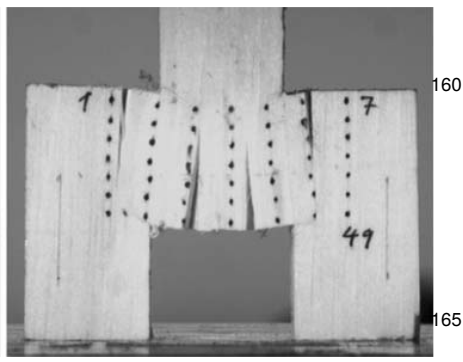

a $F$

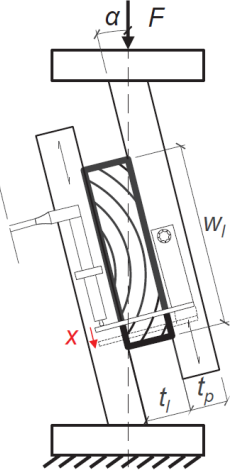

Figure 2: Notched shear block test [17] (top), Arcan shear test [17] (bot. left) and Single-lap shear test (bot. right) [23]

to $30 \mathrm{MPa}$ approximately using video extensometry. In a following study, Dahl and Malo [27] measured an average rolling shear strength of 1.6 MPa. From these results, Dahl and Malo [17] observed that the Arcan shear test seems one of the most reliable test to estimate local shear strength ${ }^{185}$ and stiffness of wood. This testing technique was recently improved by measuring the strain field on both faces of the sample which significantly reduces the dispersion of the rolling shear modulus determination [28].

Lastly, an alternative test to measure the local sheariso moduli of Norway Spruce has been used by Keunecke et al. [29]. The Young and shear moduli are derived from the measurement of sound velocity of longitudinal waves and transverse waves respectively in a small cubic specimen (10 $\mathrm{mm}$ in each material direction). In particular, they ${ }^{195}$ measured a local rolling shear modulus of $53 \mathrm{MPa}$. These approaches were recently reviewed by Longo et al. [30].

\subsection{Tests at the individual board scale}

All previously mentioned studies were about the local ${ }^{200}$ rolling shear modulus $G_{R T}$. However, the minimal scale for estimating the equivalent layer cross shear modulus $G_{C Z}$ is a single board.

In this direction, Aicher and Dill-Langer [14] then Jakobs et al. [31] studied numerically the effect of the ${ }^{205}$ sawing pattern, defined as the distribution of ring orientation in the section, on the equivalent layer shear modulus perpendicular to the grain. They simulated numerically the single lap shear test of softwood specimen [32]: the board size specimen is glued between two plates moving laterally respectively to each other in order to shear the specimen (Figure 2). The shear modulus is estimated from the relative displacement between the two plates. They estimated an equivalent cross-layer shear modulus between $45 \mathrm{MPa}$ and $350 \mathrm{MPa}$ whereas the input local rolling shear modulus was set at $50 \mathrm{MPa}$. They observed maximum values for sawing patterns with annual ring orientations at $45^{\circ}$. These observations were confirmed by the experimental work of Ehrhart et al. [23] on single lap shear tests and of Franzoni et al. [11] on double lap shear test and the experimental and numerical work of Görlacher [33] by means of eigenfrequencies.

Furthermore, Jakobs et al. [31] then Ehrhart et al. [23] observed that the increase of the board aspect ratio, defined as the ratio between width and thickness, as well as the decrease of the radial distance to the pith lead to an increase of the effective shear modulus. Moreover, an increase of the shear strength is also observed when increasing board aspect ratio. From these observations, Ehrhart et al. [23] recommend to set the effective shear modulus and strength according to linear functions of the board aspect ratio revised later by Schickhofer et al. [34]. In a recent study, Perret et al. [16] suggest closed-form bounds of the equivalent cross-layer shear moduli of timber depending on the sawing pattern and on local mechanical characteristics at ring scale. They observe particularly that, if the board is cut relatively close to the pith, the equivalent cross-layer shear modulus lies between 100 and $150 \mathrm{MPa}$.

Therefore, single or double lap shear tests appear relevant for measuring the equivalent layer shear modulus and strength of boards which depend on the width to depth ratio and on the radial distance to the pith. However, these tests are very sensitive to geometric imperfections mostly related to wood heterogeneity and variability. Indeed, parasitic bending moments may occur and introduce nonlinear response. In order to mitigate these effects, Mestek [35] suggested modifications, followed in [23], such as the angle between the applied force and the plate orientation as well as the plate's geometry.

Furthermore, in all these studies, properties of boards are measured individually leading to a high coefficient of variation (between 20 and 30\% [23, 11]) whereas there are numerous boards in a single CLT layer. Hence, regarding the plate behavior of CLT, an averaging effect is expected and the corresponding lower dispersion for the elastic moduli may be taken into account in design guidelines. For instance, Zhou et al. [36] observed a smaller coefficient of variation of $16.5 \%$ from single-lap shear test 
on wooden cross layer made of several boards with glued narrow edges.

These observations suggest that tests on full-size spec-260 imen may be more relevant to measure the shear behavior of CLT panels.

\subsection{Tests at the beam scale}

According to NS-408 [37], the elastic shear modulus parallel to the grain of a solid wood or GLT beam $\operatorname{can}^{265}$ be calculated from two consecutive bending tests. First, a four-point bending test with a slenderness larger than 18 where the bending stiffness is calculated from relative the pure bending area between applied loads. Second, a three-point bending test on the same sample with ${ }^{270}$ a slenderness of 5 where the apparent stiffness, including the bending stiffness and the shear force stiffness (related to the shear modulus parallel to the grain), is calculated from gested by Yoshihara et al. [38], Yoshihara and Kubojima ${ }^{275}$ [39] where beams are tested under three-point bending, asymmetric four-point bending or five-point bending tests [40] with varying span to depth ratio. These tests provide higher ratio of shear stress to bending stress and then a higher relative shear deflection. Nevertheless, the Saint ${ }^{28}$ Venant's principle can be violated during these tests because of small slenderness leading to a non reliable shear correction factor in the Timoshenko beam theory as obby Yoshihara et al. [38]. More recently, Brandner et al. [41, 42] followed by Gehri [43] applied the standard ${ }^{285}$ from NS-408 [37] complemented with digital image correlation measuring the shear strain field of GLT beam under four-point bending. They compared these measurements of the elastic shear modulus parallel to the grain to those obtained from torsion tests.

All preceding test were conducted for deriving the elastic shear modulus of solid wood or GLT parallel to the grain. Regarding CLT panels, which should be considered behavior of 3-ply beams under three-point bending with ${ }^{295}$ varying span to depth ratio. They compared the measured deflection to the theoretical deflection given by the shear analogy method. They used the equivalent cross-layer tests and longitudinal layer modulus measured by means ${ }^{300}$ of vibration tests. Nevertheless, they observed that the deflection is overestimated by the shear analogy method: the estimated deflection is $64 \%$ to $11 \%$ higher than the measured deflection for span to depth ratio from 6 to 14 .

In addition to the relevant beam model for correctly capturing shear strains, measurement made directly on $_{305}$
CLT panels inevitably mixes two kinds of shear strains: parallel and perpendicular to the grain. It is thus very difficult to directly identify the rolling shear contribution. As a conclusion, tests on CLT beams can be used to verify assumptions on the global shear behavior of the CLT but they are not relevant to measure individually the shear behavior of each layer.

\subsection{Tests at a single layer scale}

We present here a new methodology to estimate the equivalent cross-layer shear modulus of timber: a bending test on a sandwich beam composed of a thick wooden cross-layer core glued between two thin CFRP skins (Figure 3). The aim of this methodology is to isolate the cross-layer in order to characterize exclusively its shear behavior. Indeed, when the contrast is sufficient, the skins contribute mainly to the bending stiffness and the core mostly affects the shear force stiffness of the sandwich beam. Thus the shear deflection is only due to the inner cross-layer, contrary to CLT beams where it is mixed between shear effects in longitudinal layers and in cross layers. As a consequence, the equivalent cross-layer shear modulus of the wooden core as well as the composite skins stiffness can be directly estimated from a four-point bending test of the sandwich beam. A similar approach was applied for determining the contribution of the polyvinyl butyral layer to the shear behavior of laminated glass [44].

Moreover, replacing the CLT longitudinal layers by CFRP ensures that the bending stiffness is well controlled. Indeed CFRP present low material variability and creep is mitigated in the longitudinal direction in contrast to longitudinal layers in CLT beams. Besides, the variability of the wooden core is closest to the actual behavior of crosslayers of CLT than that of single lap shear tests because it is made of numerous boards. Indeed, this variability is lower and it would be beneficial for timber industry to have smaller safety coefficients.

Finally, we investigate a new measurement of the bending stiffness from the rotation at beam supports which will prove more reliable than the measurement from the relative deflection between loads since it is a direct measure - not mixed with shear behavior - and it averages the bending behavior on the whole span of the beam. In this paper, only the short term elastic behavior is presented but the methodology is already under application for creep tests.

\section{Identification by four-point bending of homogeneous sandwich beam}

Here, we consider that characteristics at board scale are homogeneous to analyze the behavior of a sandwich beam 


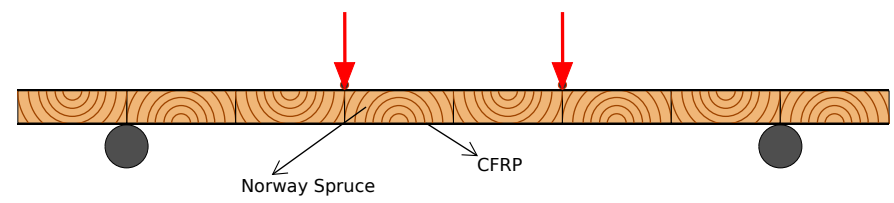

Figure 3: Four-point bending of a CFRP sandwich beam with wooden core

under four-point bending. Basic features of sandwich theory are first recalled and their hypotheses are validated by means of a reference 3D finite element model. The numerical model is also used to investigate the deterministic sensitivity of the identification procedure to input characteristics and local effects.

\subsection{The sandwich beam model}

The main features of the sandwich beam model are recalled here, more details can be found in [45]. The studied sandwich beam is composed of a thick homogeneous wooden core of thickness $t_{c}$ between two thin CFRP skins of thickness $t_{s}$ (Figure 4 and 5). The total thickness is noted $h=t_{c}+2 t_{s}$ and the width is noted $b$. Cartesian coordinates $x, y, z$ are used in the reference frame $\left(\underline{e}_{x}, \underline{e}_{y}, \underline{e}_{z}\right)$ where $x$ is the abscissa in the longitudinal direction of the beam and $y$ and $z$ are the coordinates in the section of the beam.
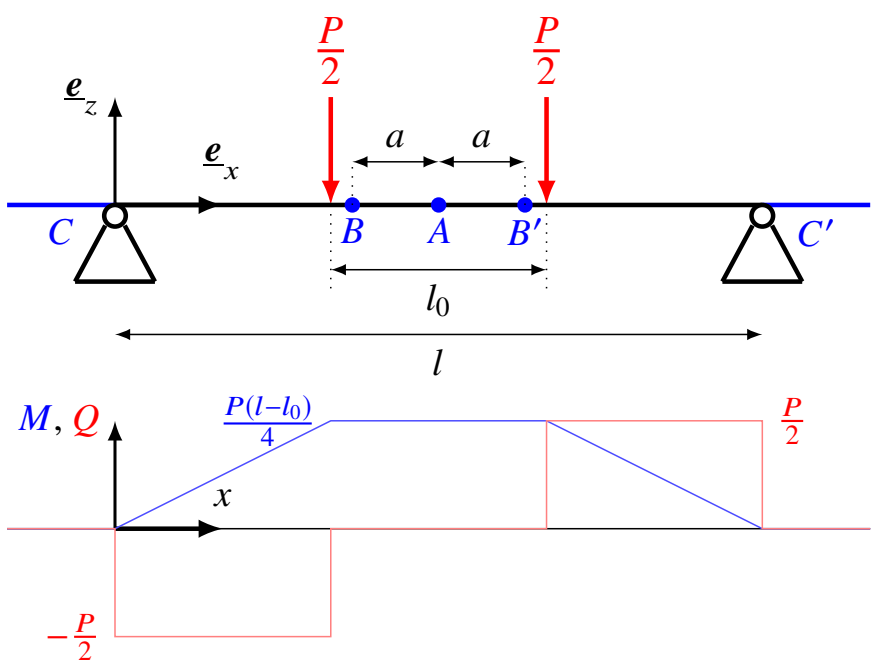

Figure 4: Four-point bending configuration and diagrams

Among the 9 elastic moduli of the wooden core and the 5 elastic moduli of CFRP, which is modeled as transversely isotropic, only the Young moduli in the beam longitudinal direction and the shear moduli in plane $x-z$ are necessary in the beam model. They are noted in this section $\left(E_{s}, G_{s}\right)$ for the skins and $\left(E_{c}, G_{c}\right)$ for the core. In the sandwich ${ }^{325}$

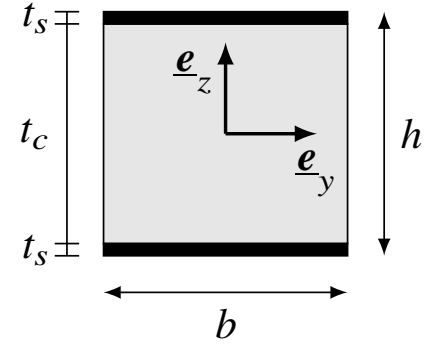

Figure 5: Cross section of the sandwich beam

beam model [46], a stiffness and a thickness contrasts are assumed between the core and the skins such that:

$$
E_{s} t_{s} \gg E_{c} t_{c}, \quad t_{c} \gg t_{s} .
$$

Considering here $E_{s}=110 \mathrm{GPa}, E_{c}=0.43 \mathrm{GPa}, t_{c}=$ $30 \mathrm{~mm}$ and $t_{s}=1.2 \mathrm{~mm}$, these conditions are satisfied. Hence, because of these contrasts, the skins contribute mainly to the bending stiffness $D$ whereas the core mostly affects the shear force stiffness $F$ as recalled from Allen [46]:

$$
\left\{\begin{array}{l}
D \approx \frac{b\left(h^{3}-t_{c}^{3}\right)}{12} E_{s}, \\
F \approx \frac{b\left(t_{c}+t_{s}\right)^{2}}{t_{c}} G_{c} .
\end{array}\right.
$$

The bending moment $M$ and the shear force $Q$ are classically defined by:

$$
\left\{\begin{array}{l}
M(x)=-\int_{-\frac{h}{2}}^{\frac{h}{2}} z \sigma_{x x}(x, z) b \mathrm{~d} z, \\
Q(x)=\int_{-\frac{h}{2}}^{\frac{h}{2}} \sigma_{x z}(x, z) b \mathrm{~d} z .
\end{array}\right.
$$

Approximations of the bending stress $\sigma_{x x}$ and the shear stress $\sigma_{x z}$ are derived according to Jouravskii [13] method:

$$
\left\{\begin{array}{l}
\sigma_{x x}(z)=-\frac{M E(z)}{D} z, \\
\sigma_{x z}(z)=-\frac{Q}{D} \int_{-\frac{h}{2}}^{z} \zeta E(\zeta) \mathrm{d} \zeta .
\end{array}\right.
$$

Furthermore, considering the stiffness contrast (1), the shear stress $\sigma_{x z}$ (4b) can be approximated as uniform in the wooden core by:

$$
\sigma_{x z}^{c} \approx \frac{Q}{b\left(t_{c}+t_{s}\right)} .
$$

In Figure 6, this approximated shear stress $\sigma_{x z}^{c}$ is compared to the shear stress distribution calculated from Jouravskii method (4b). For the studied specimen (Section 3), the difference is lower than $1 \%$ in the core. 


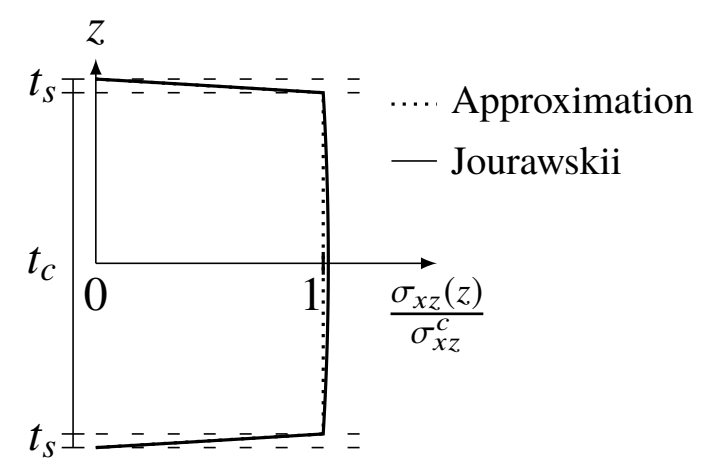

Figure 6: Jouravskii [13] distribution of shear stress $\sigma_{x z}$ in the wooden ${ }^{335}$ core and approximation of the stress $\sigma_{x z}^{c}$ in the core

\subsection{The four-point bending test}

Different measures allowing the determination of the bending and shear force stiffnesses from the four-point bending test are now presented. The beam of length $L$ is simply supported on a span $l<L$ and submitted to two loads $\frac{P}{2}$ placed symmetrically at a distance $\frac{l_{0}}{2}$ from the mid-span (Figure 4).

The beam is under pure bending between the two loads leading to a constant curvature. The bending stiffness $D$ is then directly related to the relative deflection between the mid-span (point $\mathrm{A}$ in Figure 4) and a point distant to the mid-span of a length $a<\frac{l_{0}}{2}$ (points $B$ and $B^{\prime}$ in Figure 4):

$$
\Delta f=f_{A}-\frac{f_{B}+f_{B^{\prime}}}{2}
$$

where $f_{A}, f_{B}$ and $f_{B}^{\prime}$ are absolute deflections at points $A$, $B$ and $B^{\prime}$. The corresponding estimation of the bending stiffness is:

$$
D=\frac{P\left(l-l_{0}\right)}{8 \Delta f} a^{2},
$$

In the pure bending area, the bending stiffness $D$ is also directly related to the difference of strains between the lower face in tension and the upper face in compression of CFRP skins:

$$
\Delta \varepsilon=\varepsilon_{x x}\left(-\frac{h}{2}\right)-\varepsilon_{x x}\left(+\frac{h}{2}\right) .
$$

The corresponding estimation of the bending stiffness is:

$$
D=\frac{P\left(l-l_{0}\right) h}{4 \Delta \varepsilon} .
$$

Moreover, at beam supports ( $C$ and $C^{\prime}$ in Figure 4$)$, the bending moment $M$ and the shear force $Q$ vanish and rotations $\varphi_{C}$ and $\varphi_{C^{\prime}}$ at supports $C$ and $C^{\prime}$ may be directly identified to the beam inclination. The relative rotation of the section at beam supports:

$$
\Delta \varphi=\varphi_{C}-\varphi_{C^{\prime}}
$$

is related to the bending stiffness $D$ by:

$$
D=\frac{P\left(l^{2}-l_{0}^{2}\right)}{8 \Delta \varphi} .
$$

The relative accuracy of these different measures will be discussed in Sections 2.3.3 and 4.

Since the global deflection includes bending and shear deflections, the shear force stiffness $F$ of the beam can be expressed as function of the mid-span deflection $f_{A}$ and the bending stiffness $D$ :

$$
\frac{1}{F}=\frac{4 f_{A}}{P\left(l-l_{0}\right)}-\frac{1}{8 D}\left(l^{2}-\frac{1}{3}\left(l-l_{0}\right)^{2}\right),
$$

where $D$ is derived either from $\Delta f, \Delta \varepsilon$ or $\Delta \varphi$ according to $(7,9,11)$.

The bending stiffness $D$ is inversely proportional to $\Delta f, \Delta \varepsilon$ and $\Delta \varphi$ according to $(7,9,11)$ respectively. Thus small relative variations of $\Delta f, \Delta \varepsilon$ or $\Delta \varphi$ will lead to relative variations of the estimated bending stiffness $D$ of the same order of magnitude. In contrast, according to (12), the shear force stiffness $F$ is calculated from the difference between the deflection $f_{A}$ and the estimated bending deflection at mid-span. For the studied specimen, the shear deflection $\frac{P\left(l-l_{0}\right)}{4 F}$ is approximately one third of the total deflection $f_{A}$. Thus, considering that the total deflection $f_{A}$ does not vary, small relative variations of $\Delta f$, $\Delta \varepsilon$ or $\Delta \varphi$ will lead to relative variations of the estimated shear force stiffness $F$ twice larger. Similarly, considering that $\Delta f, \Delta \varepsilon$ or $\Delta \varphi$ do not vary, small relative variations of $f_{A}$ will lead to relative variations of the estimated shear force stiffness $F$ three times larger. Thus it is observed that the predicted shear force stiffness $F$ is more sensitive than $D$, to variations of $\Delta f, \Delta \varepsilon, \Delta \varphi$ and $f_{A}$. Hence, a fine estimation of the bending stiffness $D$ and of the mid-span deflection $f_{A}$ is necessary to predict properly the shear force stiffness $F$.

More specifically, this remark reveals that measuring the bending stiffness $D$ from the relative deflection $\Delta f-$ while commonly used in practice - is not desirable in the present situation. Indeed, in order to measure a significant contribution of shear effects in the total deflection $f_{A}$, it is necessary to increase as much as possible the bending stiffness of the sandwich beam (this is the role of the CFRP skins). As a consequence, the corresponding relative deflection $\Delta f$ must be small compared to $f_{A}$. 
From the definition of $\Delta f$ (Eq. 6) it is clear that the latter ${ }_{415}$ is likely to be polluted by measurement errors as will be experimentally confirmed.

\subsection{Validation of the sandwich beam model with a $3 D$ finite element model}

In this section, the validity of the sandwich beam model is investigated by means of a 3D model with the geometry of samples used in the experimental study presented in Section 3.1.

\subsubsection{The 3D model}

The beam is modeled by a core perfectly bounded with two skins into the finite elements software ABAQUS.

Cylinders corresponding to supports and loads are modeled as rigid cylindrical shells. Supports are fixed while«з intermediate cylinders moving vertically are loaded with $P / 2$. A frictionless tangent contact is set between the beam and the cylinders.

An incremental static analysis is performed with a starting increment of $1 \%$ of the total load $P=1 \mathrm{kN}$. Non-435 linear geometric effects are taken into account in the calculation of the deformed state in order to handle contact interactions.

The beam is meshed with 3D cubic elements C3D20R [47] with twenty nodes and reduced integration on 8 points. .40 Figure 7 shows that the mesh is finer close to contact areas to better capture local stresses and strains in these boundary layers.

Both materials are modeled as transversely isotropic (Table 1): the skins are isotropic in the plane $\left(O, \underline{e}_{y}, \underline{e}_{z}\right)$ and 445 the core is isotropic in the plane $\left(O, \underline{e}_{x}, \underline{e}_{z}\right)$. The mechanical characteristics of the wooden core are in agreement with the experimental study of Franzoni et al. [11] and 400 with Reuss and Voigt bounds calculated by Perret et al. [16].

Only one fourth of the beam is simulated because of planes of symmetry normal to $\underline{e}_{x}$ and to $\underline{e}_{y}$.

\subsubsection{Accuracy of the stress estimation in the core}

In this paragraph, the stress distribution in the wooden $_{455}$ core of the beam is studied in order to check if the shear stress is almost uniform in the core between supports and loads and if the bending stress in the core is negligible in agreement with the main hypotheses of the sandwich beam theory.

In Figure 7, the relative error of the transverse shear stress $\sigma_{x z}$ in one half of the beam is plotted with respect to the sandwich beam estimation $\sigma_{s}=\frac{P}{2 b\left(t_{s}+t_{c}\right)}(5)$. It is observed that, in approximately $90 \%$ of the area between support and load, the relative difference between the predicted shear stress $\sigma_{s}$ and the 3D reference shear stress is within $10 \%$. As expected, fast variations are observed close to contacts with cylinders.

In Figure 8, distributions of the transverse shear stress are plotted along the $x$ axis at three locations: at neutral fibre level in the wooden core and at fibers close to the interface between wood and composites at $z= \pm \frac{7 t_{c}}{16}$ (yellow lines in Figure 7). The origin of the abscissa is located at the support, the load is applied at $200 \mathrm{~mm}$ from the support, $-100 \mathrm{~mm}$ is the free extremity of the beam. Boundary layers are observed close to supports and loads, they are getting smaller close to the neutral axis. From these figures, the sandwich beam hypothesis of a constant shear stress distribution in the wooden core is globally satisfied.

In Figures 9 and 10, the bending stress $\sigma_{x x}$, the transverse stress $\sigma_{z z}$ and the shear stress $\sigma_{x z}$ are plotted in the wooden core at neutral axis and on fibers close to the interface between wood and composites at $z= \pm \frac{7 t_{c}}{16}$ and in the CFRP skins on top and bottom fibers $z= \pm \frac{h}{2}$. Stresses are normalized with the corresponding strength: the transverse tensile, compressive and rolling shear strength of wood are set to $\sigma_{c r, 90, t}=1.8 \mathrm{MPa}$, to $\sigma_{c r, 90, c}=3.0 \mathrm{MPa}$ and to $\sigma_{c r, R T}=1.7 \mathrm{MPa}$ respectively according to Franzoni et al. [11] work; the transverse compressive and tensile strength of CFRP skins are set to $50 \mathrm{MPa}$.

High stress concentrations are observed at contact areas on top fiber under the load and on bottom fiber on support. Particularly, a maximum compressive transverse stress $\sigma_{z z}$ of $60 \%$ of the compressive strength is observed in CFRP skins due to the small contact area with cylinders. This high stress could lead to local punching of CFRP skins. In the experimental setup (Section 3.2) metal plates are therefore set between cylinders and specimen during tests reducing up to six times this local stress in skins and to twice the local stress in the wooden core according to a complementary 3D finite element study (not shown here for conciseness).

Nevertheless, in the area between supports and loads, the wooden core is mostly sheared. Neglecting local stress concentration close to contact areas and considering its linear distribution through thickness, the average bending stress $\sigma_{x x}$ in the wooden core is approximately $1.7 \%$ of the compressive strength and $2.9 \%$ of the tensile strength between support and load. The transverse stress $\sigma_{z z}$ is very low, lower than $1 \%$ of the strength, in the major part of the section between load and supports. In contrast, the average shear stress is approximately $24 \%$ of the rolling shear strength. Thus, the assumption of a pure shear state in the core between load and support is admissible as first 


\begin{tabular}{cccccccccc}
\hline (MPa) & $E_{x}$ & $E_{y}$ & $E_{z}$ & $G_{y z}$ & $G_{x z}$ & $G_{x y}$ & $v_{y z}$ & $v_{x z}$ & $v_{x y}$ \\
\hline CFRP & 115000 & 7000 & 7000 & 2700 & 4000 & 4000 & 0.3 & 0.3 & 0.3 \\
Wood & 325 & 12700 & 325 & 600 & 110 & 600 & 0.43 & 0.48 & 0.43 \\
\hline
\end{tabular}

Table 1: Elastic moduli of wood and CFRP used in FE simulations

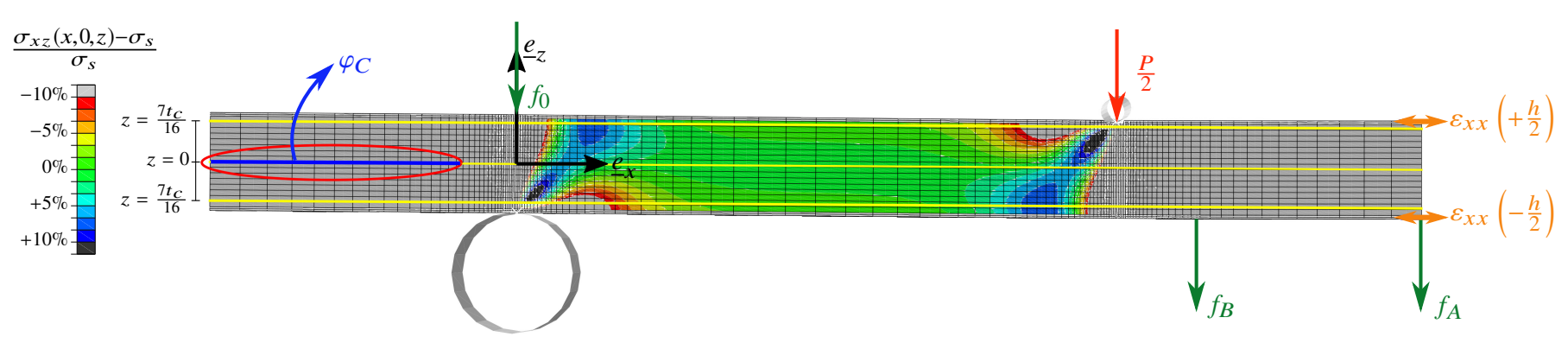

Figure 7: 3D shear stress distribution $\sigma_{x z}(x, 0, z)$ compared to sandwich beam estimation $\sigma_{s}$

approximation compared to averaged bending and transverse stress.

\subsubsection{Accuracy of the global deflection estimation}

The deflection of the sandwich beam is observed for a total applied load $P$ of $1 \mathrm{kN}$ corresponding to $24 \%$ of the rolling shear failure measured in [11] and to a maximum 500 deflection of $2 \mathrm{~mm}$ approximately. Kinematic variables $\Delta \varphi, \Delta f, f_{A}$ and $\Delta \varepsilon$ are evaluated by the three-dimensional results on locations pointed in Figure 7 and corresponding to the sensors locations during experiment (Section 3).

- $\Delta f, f_{A}$ are given by deflections of the lower fiber at ${ }_{505}$ $x=\frac{l}{2}-a\left(f_{B}\right)$ and $x=\frac{l}{2}\left(f_{A}\right)$

- $\Delta \varepsilon$ is extracted from the longitudinal strains on top and bottom fibers at mid-span section;

- The rotation $\Delta \varphi$ is calculated from a linear regres-510 sion of the deflection at neutral axis on the domain plotted in blue (Figure 7) $x \in\left[\frac{l-L}{2} ; \frac{l-L}{10}\right]$ in order to avoid boundary layers close to supports.

In Figure 11, the difference between the reference three-dimensional deflection $u_{z}(x, 0, z)$ on neutral $(z=0)$, upper $\left(z=\frac{h}{2}\right)$ and lower $\left(z=-\frac{h}{2}\right)$ axis and the deflection $f(x)$ calculated from the sandwich beam model are plotted along the beam normalized with the three-dimensional mid-span deflection $u_{z}\left(\frac{l}{2}, 0,0\right)$ at neutral axis. It is observed that the deflection approximated by the sandwich beam theory is very close to $3 \mathrm{D}$ results. Moreover, a local deflection at supports is observed. On the upper fiber, this deflection is equal to $1.4 \%$ of the total mid-span deflection. This is due to a local punching. Compared to the 525 variability of wood mechanical characteristics, the effect of this punching on the measured deflections is negligible. Indeed, the 3 deflections are very close at mid-span (the relative difference is about $0.2 \%$ ). Thus the impact of the local punching on the measurement of deflection appears negligible and there is little difference between measurements made on the upper or lower fibers.

\subsubsection{Accuracy of the modulus identification}

In order to estimate the measurement systematic error for the elastic moduli identification, the identification procedure detailed in Section 2.2 is applied to the virtual results from the finite element analysis.

First, a linear regression between the load $P$ and the kinematic variables is calculated from 3D results. Then, the bending and shear force stiffnesses $D^{\text {est }}$ and $F^{\text {est }}$ are estimated from the relative deflection $\Delta f$, the relative bending strain $\Delta \varepsilon$ at mid-span and the relative rotation at beam ends $\Delta \varphi$ according to the sandwich beam model (Equations 7, 9 and 11). Finally, from these stiffnesses, the corresponding skin Young modulus and core shear stiffness modulus are computed from Equations 2.

In Table 2, skins Young modulus $E_{x, \text { CFRP }}^{\text {est }}$ and apparent core shear modulus $G_{x z \text {,Wood }}^{\text {est }}$ estimated from the deflection measurement $\left(f_{A}, \Delta f, \Delta \varphi, \Delta \varepsilon\right)$ are compared with the input elastic parameters $\left(E_{x, \mathrm{CFRP}}, G_{x z \text {,Wood }}\right)$ of the $3 \mathrm{D}$ finiteelement model. It is first observed that the skins Young

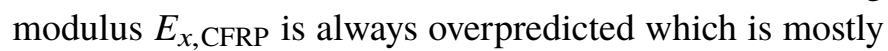
due to the sandwich beam assumptions: contribution of the wooden core in the bending stiffness is neglected. On the contrary, the core shear modulus $G_{x z \text {, Wood }}$ is always underestimated which is partly due to the assumption of negligible contribution of skins to shear compliance [46]. 


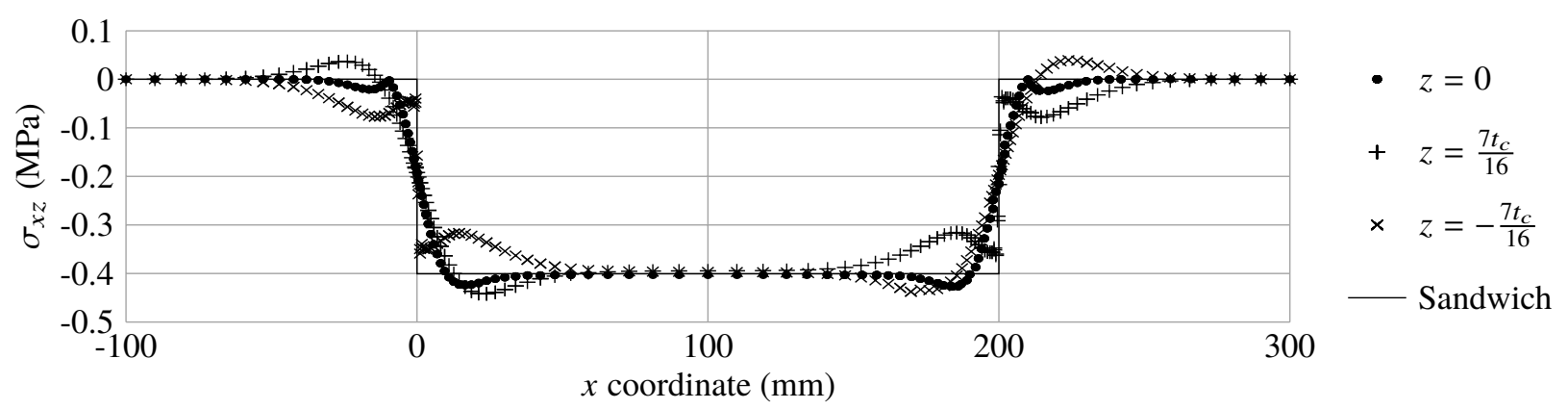

Figure 8: Shear stress $\sigma_{x z}$ along the beam for upper, lower and neutral fiber in the core from 3D and sandwich beam models

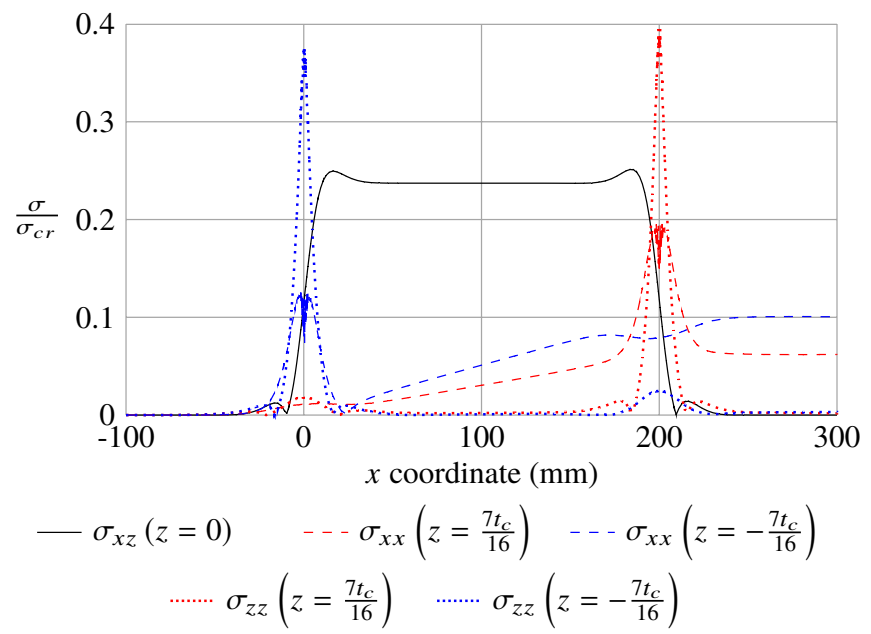

Figure 9: Distribution of stresses $\sigma_{x x}, \sigma_{z z}$ and $\sigma_{x z}$ in timber normalized with the corresponding strength

Moreover, it is observed that predictions with rotation $\Delta \varphi$ or strains $\Delta \varepsilon$ have an accuracy of $2 \%$ whereas predictions with relative deflection $\Delta f$ have an accuracy of $3.5 \%$. From the parametric study in Table 2, the relative errors of predicted moduli vary slightly according to input parameters $\left(E_{x, \mathrm{CFRP}}, G_{x z \text {, Wood }}\right)$. Particularly, it is observed that the prediction error of $E_{x, \mathrm{CFRP}}^{\mathrm{est}}$ is subjected to larger ${ }_{550}$ variations when estimated from $\Delta f$ than from $\Delta \varepsilon$ or $\Delta \varphi$.

From these comparisons and analyses, we conclude

\section{Experimental campaign}

\subsection{Specimen fabrication}

The specimen are made of a wooden core between two CFRP layers. The wood comes from samples taken from

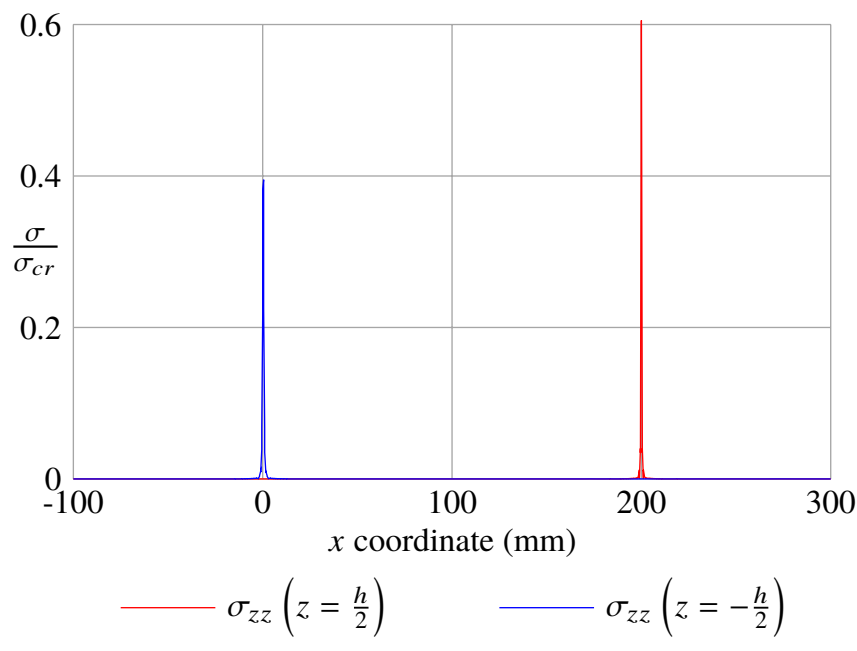

Figure 10: Distribution of stresses $\sigma_{z z}$ in CFRP normalized with the tensile and compressive strength

Franzoni et al. [11] experiments. It consists of Norway Spruce boards with a thickness of $30 \mathrm{~mm}$ and a width of $100 \mathrm{~mm}$. The samples have been previously conditioned at $20^{\circ} \mathrm{C}$ and $65 \%$ relative humidity ( $\left.\mathrm{RH}\right)$ during at least one week, so that the moisture content in boards is between 10 and $13 \%$ before gluing. Ten boards are glued on their narrow faces with a two components glue including a thixotropic epoxy based impregnating resin and an adhesive (Sikadur 330). Then, $800 \mathrm{~mm}$ long specimens with a width $b=40 \mathrm{~mm}$ and a thickness $t_{c}=30 \mathrm{~mm}$ are cut, so that the wood fibers are oriented in the transverse direction. These specimen are conditioned again at $20^{\circ} \mathrm{C}$ and $65 \%$ relative humidity $(\mathrm{RH})$ before gluing with CFRP skins. A total of 12 specimens are fabricated.

It is important to note that the present sampling is not intended to be representative either of the actual variation of the species or of the sawing pattern. It is chosen here only to illustrate the feasibility of the new methodology compared to other testing approaches.

The CFRP skins are made of six carbon fiber epoxy 


\begin{tabular}{cc|ccc|ccc|ccc}
\hline$E_{x, \text { CFRP }}$ & $(\mathrm{GPa})$ & & 110 & & & 115 & & & 120 & \\
$G_{x z, \text { Wood }}$ & $(\mathrm{MPa})$ & 105 & 110 & 115 & 105 & 110 & 115 & 105 & 110 & 115 \\
\hline \multirow{2}{*}{$E_{x, \mathrm{CFRP}}^{\text {est }}-E_{x, \mathrm{CFRP}}$} & $\Delta f$ & 3.26 & 2.93 & 2.66 & 3.24 & 2.90 & 2.63 & 3.22 & 2.88 & 2.58 \\
$E_{x, \text { CFRP }}$ & $\Delta \varphi$ & 2.02 & 2.01 & 1.99 & 1.94 & 1.93 & 1.91 & 1.87 & 1.86 & 1.84 \\
& $\Delta \varepsilon$ & 1.91 & 2.01 & 1.89 & 1.83 & 1.82 & 1.81 & 1.76 & 1.75 & 1.74 \\
\hline \multirow{2}{*}{$G_{x z, \text { Wood }}^{\text {est }}-G_{x z, \text { Wood }}$} \\
$G_{x z, \text { Wood }}$ & $\Delta f, f_{A}$ & -3.53 & -3.35 & -3.19 & -3.55 & -3.36 & -3.21 & -3.54 & -3.36 & -3.20 \\
& $\Delta \varphi, f_{A}$ & -1.27 & -1.56 & -1.84 & -1.26 & -1.56 & -1.83 & -1.26 & -1.56 & -1.83 \\
& $\Delta \varepsilon, f_{A}$ & -1.05 & -1.56 & -1.63 & -1.05 & -1.35 & -1.63 & -1.06 & -1.36 & -1.63 \\
\hline
\end{tabular}

Table 2: Relative error of the estimation of moduli $E_{x, \text { CFRP }}^{\text {est }}$ and $G_{x z \text {,Wood }}^{\text {est }}$ by the sandwich beam model compared to input variables $E_{x, \text { CFRP }}$ and $G_{x z, \text { Wood }}$

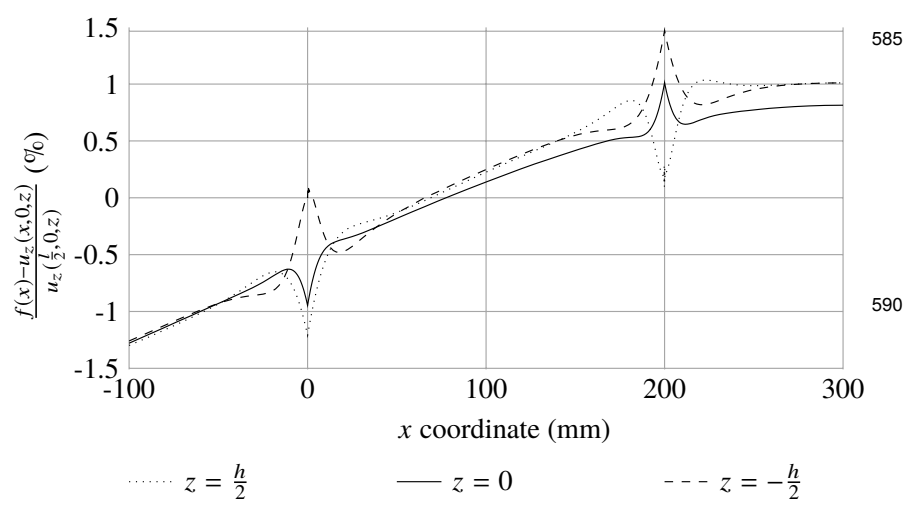

Figure 11: Relative deflection between sandwich and 3D model nor- ${ }^{595}$ malized with the mid-span deflection

prepreg sheets stacked and cured at $120^{\circ} \mathrm{C}$ during 90 min$L=800 \mathrm{~mm}$, a width $b=40 \mathrm{~mm}$ and a thickness $t_{s}=1.2 \mathrm{~mm} \pm 0.2 \mathrm{~mm}$. Two sets of CFRP skins with ${ }^{600}$ different mechanical properties are used in this study (One for specimens RS1-1 to RS1-3, the others for specimens RS2-1 to RS2-9).

Finally, for each wooden specimen, the CFRP skins are glued on the top and bottom faces of timber with the same glue as for timber's narrow edges during 24 hours. The thickness of the glue layer is measured thinner than . As observed in Figures 3 and 12, boards are carefully oriented, so that the pith is alternatively at the bottom and top faces of the specimen in order to mitigate their effect on the global behavior.

\subsection{Experimental setup}

The experimental setup is presented in Figure 12. Specimen are supported on two cylinders of radius $R=$ $20 \mathrm{~mm}$ on a span $l=600 \mathrm{~mm}$. They are loaded vertically and symmetrically by two cylinders of radius $r=4 \mathrm{~mm}$ spaced of a length $l_{0}=200 \mathrm{~mm}$. Steel plates are placed ${ }_{605}$ between specimen and cylinders to mitigate local punching. Several sensors are positioned to measure variables introduced in Section 2:

- Five linear variable differential transformers (LVDTs) are placed on the frame. Three of them measure the vertical deflection on the lower axis of the beam: one at mid-span $\left(f_{A}\right)$, the two others on both sides at a distance $a=80 \mathrm{~mm}$ from the mid-span $\left(f_{B}\right.$ and $f_{B^{\prime}}$ ). The two remaining LVDTs are located on the upper axis to measure the vertical settlement on supports.

- Two inclinometers are screwed into the wooden core on cantilevers on both sides of the specimen to measure the end rotation $\left(\varphi_{C}\right.$ and $\left.\varphi_{C^{\prime}}\right)$;

- Two strain gauges are glued on the upper $\left(\epsilon_{11}^{+}\right)$and the lower skins $\left(\epsilon_{11}^{-}\right)$close to the mid-span.

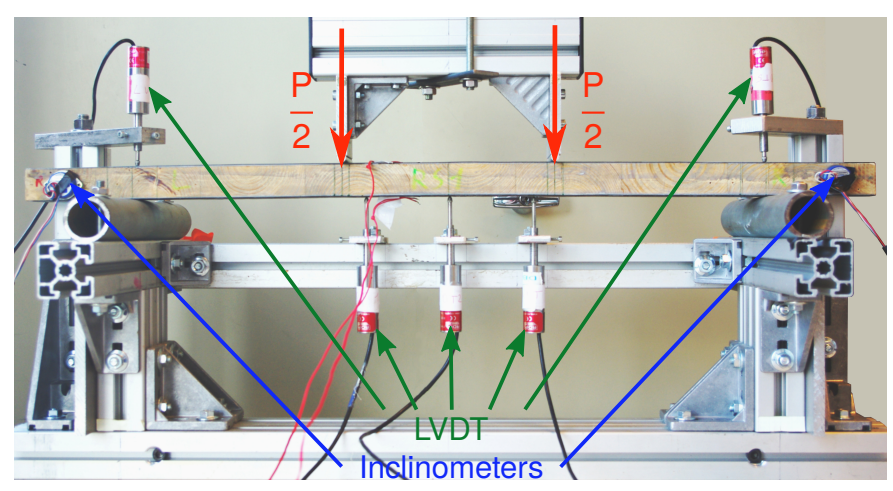

Figure 12: Experimental setup

The specimen is loaded with a monitored vertical displacement up to $2.5 \mathrm{~mm}$, then unloaded to $1.0 \mathrm{~mm}$, next reloaded to $2.5 \mathrm{~mm}$ and finally totally unloaded (Figure 13). Thus, the specimen is never loaded more than $30 \%$ of the failure load measured by Franzoni et al. [11] at 
1.7 $\mathrm{MPa}$ in order to remain within the elastic range. The testing speed is set to $3 \mathrm{~mm} / \mathrm{min}$ so that the measurement time is approximately one minute to mitigate viscoelastic effects. Moduli measurements are derived from the reloading steps to avoid rigid body motions and tolerance recovering by linear regression between the load $P$ and $\Delta f, \Delta \varphi, \Delta \varepsilon$ and $f_{A}$.

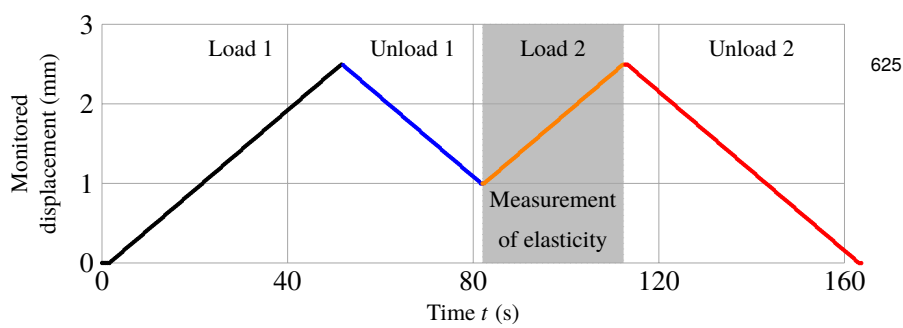

Figure 13: Experimental loading sequence

\subsection{Identification of bending and shear force stiffnesses with the four-point bending test}

Each specimen is made of several boards with different mechanical properties because of annual rings as well as natural variations of wood which for the moment were not taken into account in the model. To consider these variations, it is possible to go further than in Section 2 and to assume that the bending stiffness $D(x)$ and the shear force stiffness $F(x)$ vary slowly along the beam. Thus, $D^{630}$ and $F$ measured from relative deflection $\Delta f$, rotation at supports $\Delta \varphi$, bending strains $\varepsilon_{x x}$ and mid-span deflection $f_{A}$ (Section 2.2) are actually averaged properties of the beam. By means of Castigliano theorem, it can be shown that the measured bending stiffness $D_{\Delta f}(7), D_{\varepsilon}(9), D_{\varphi}$ (11) and $D_{f}$ (12) and the measured shear force stiffness $F_{f}(12)$ are the following averages of the local bending stiffness $D(x)$ and shear force stiffness $F(x)$ :

$$
\begin{aligned}
& \frac{1}{D_{\Delta f}}=\frac{1}{a} \int_{0}^{l} \frac{w_{\Delta f}(x)}{D(x)} \mathrm{d} x, \\
& \frac{1}{D_{\varphi}}=\frac{2}{l+l_{0}} \int_{0}^{l} \frac{w_{\varphi}(x)}{D(x)} \mathrm{d} x, \\
& \frac{1}{D_{\varepsilon}}=\frac{1}{D\left(\frac{l}{2}\right)}, \\
& \frac{1}{D_{f}}=\frac{2 l}{l^{2}-\frac{\left(l-l_{0}\right)^{2}}{3}} \int_{0}^{l} \frac{w_{f, D}(x)}{D(x)} \mathrm{d} x, \\
& \frac{1}{F_{f}}=\frac{1}{l-l_{0}} \int_{0}^{l} \frac{w_{f, F}(x)}{F(x)} \mathrm{d} x,
\end{aligned}
$$

where, $w_{\Delta f}(x), w_{\varphi}(x), w_{f, D}$ and $w_{f, F}$ can be considered 650 as weight functions plotted in Figure 14
From these distributions, the equivalent compliance $\frac{1}{D_{\varphi}}$ is a weighted average of $\frac{1}{D(x)}$ on the whole span $l$ of the beam whereas $\frac{1}{D_{\Delta f}}$ is a weighted average on a length $2 a$ only. Thus, the measurement of the bending compliance with the relative deflection $\Delta f$ is more sensitive to variations of the wood mechanical characteristics than the measurement from rotation at supports $\Delta \varphi$. It is interesting to note that $D_{\varepsilon}$ is a local measurement of the bending stiffness and is therefore rather sensitive to local variations.

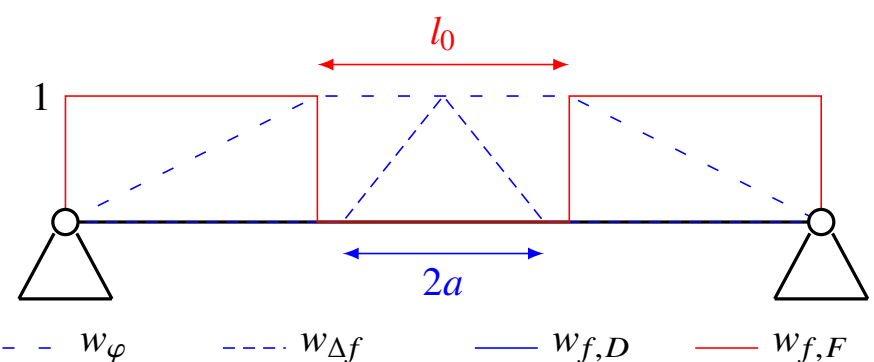

Figure 14: Weight functions for the integration of the bending compliance and the shear compliance over the beam

It can thus be concluded that, since there is a variability of wood characteristics in CLT cross-layer, the estimation of $D$ based on $\Delta \varphi$ will be more reliable and will a priori present a reduced standard deviation compared to estimations with $\Delta f$ and $\Delta \varepsilon$. This will be confirmed in Section 4 .

\section{Determination of the equivalent cross-layer shear modulus}

\subsection{Deflections and rotations during loading and unload- ing}

In this section, results are plotted during the whole experiment in order to discuss the quality of the measurements and to determine the best data for the determination of the elastic linear behavior of the sandwich beam. Results are plotted for the experiment RS1-3.

Load displacement curves of the four steps of the experiment detailed in Figure 13 are plotted for various kinematic data in Figures 15 to 20. In most cases, a slope difference is observed between the first loading step and the following steps. This is significant in Figures 15, 16, and 20. Indeed, the first loading is usually overlooked because of several phenomena:

- plastic deformations at supports and under loads due to stress concentration,

- non-linear geometrical deformations due to Hertzian contact between a rigid cylinder and the beam which affects only the early stage of the loading, 
- settlement effects during the first loading due to contact imperfections at the beginning of the experiment.

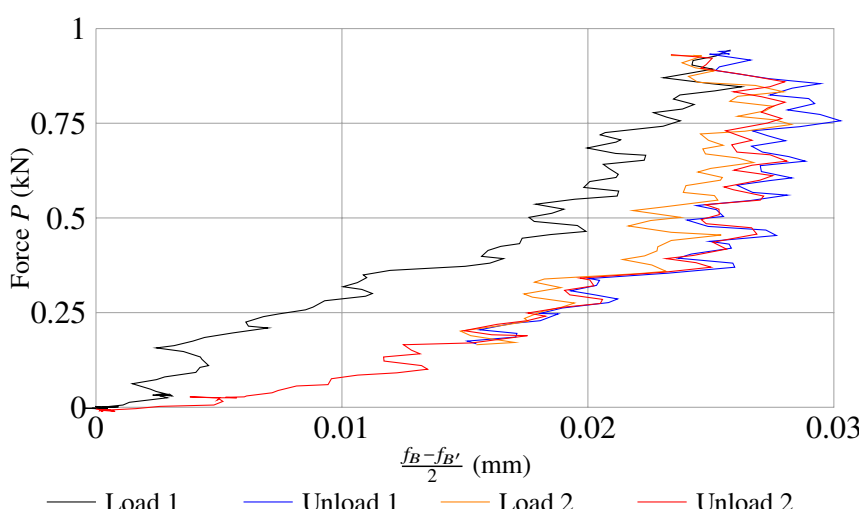

Figure 15: Applied force as function of skew-symmetric deflection at $B$ and $B^{\prime}$

More specifically in Figure 15, the force $P$ is plotted as a function of the skew-symmetric part of the deflection $\frac{f_{B}-f_{B^{\prime}}}{2}$. It appears that the skew-symmetric deflection is not negligible compared to the relative deflection $\Delta f$ (Figure 20): $\frac{f_{B}-f_{B^{\prime}}}{2 \Delta f} \sim 50 \%$. This shows the necessity of two LVDTs on both sides of the specimen. Since a great part of this deflection is due to inelastic deformations during the first loading, after this step, the skew-symmetric deflection remains relatively constant when $P>0.5 \mathrm{kN}$.

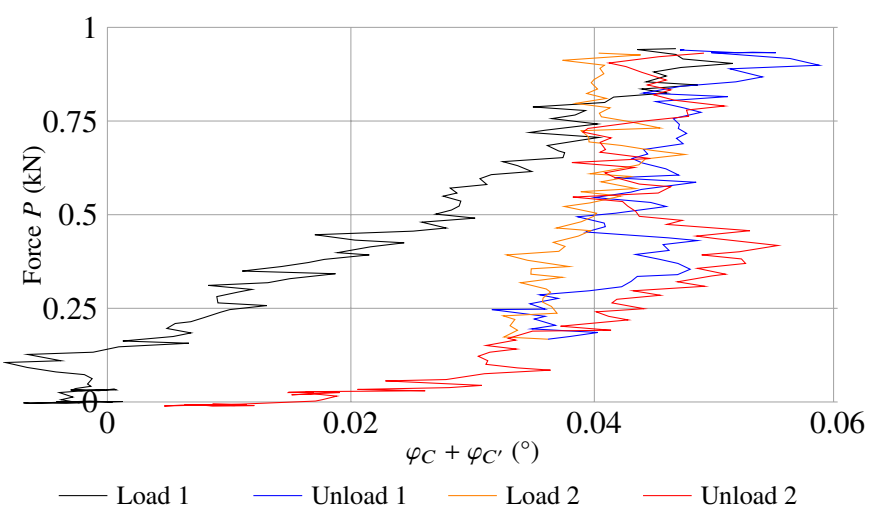

Figure 16: Applied force as function of the sum of rotations at support

Similarly, in Figure 16, the force $P$ is plotted as a function of the sum of end rotations $\varphi_{C}+\varphi_{C^{\prime}}$. Again, most of this global rotation is due to the inelastic deformations during the first loading phase. Nevertheless, it remains small compared to the relative rotation $\Delta \varphi$ (Figure 18): $\left(\varphi_{C}+\varphi_{C^{\prime}}\right) / \Delta \varphi \sim 3 \%$.

The mid-span deflection $f_{A}$ (Figure 17), the relative rotation $\Delta \varphi$ (Figure 18) and the relative deformation $\Delta \varepsilon$ (Figure 19) are rather smooth and mostly linear measurements.

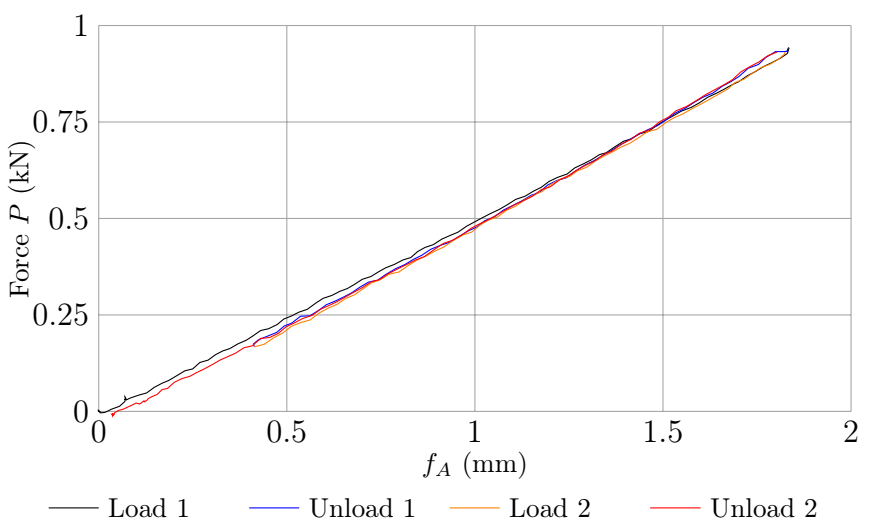

Figure 17: Applied force as function of mid-span deflection $f_{A}$

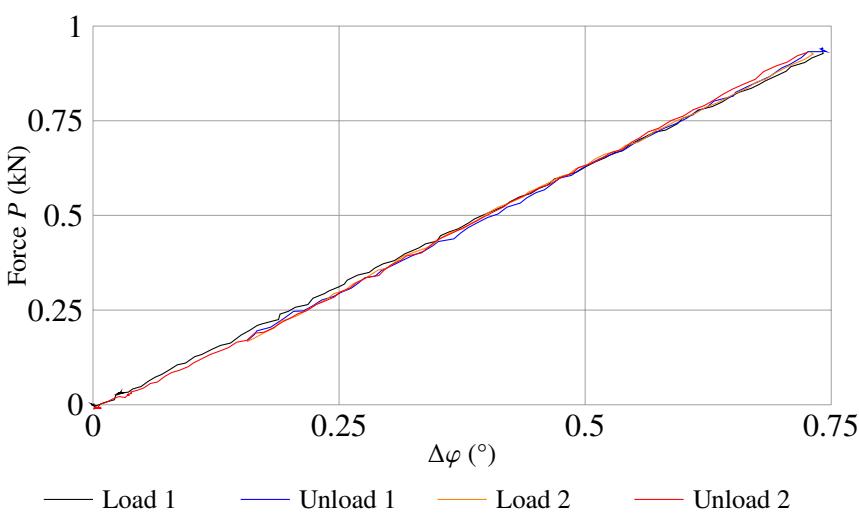

Figure 18: Applied force as function of relative rotation at support $\Delta \varphi$

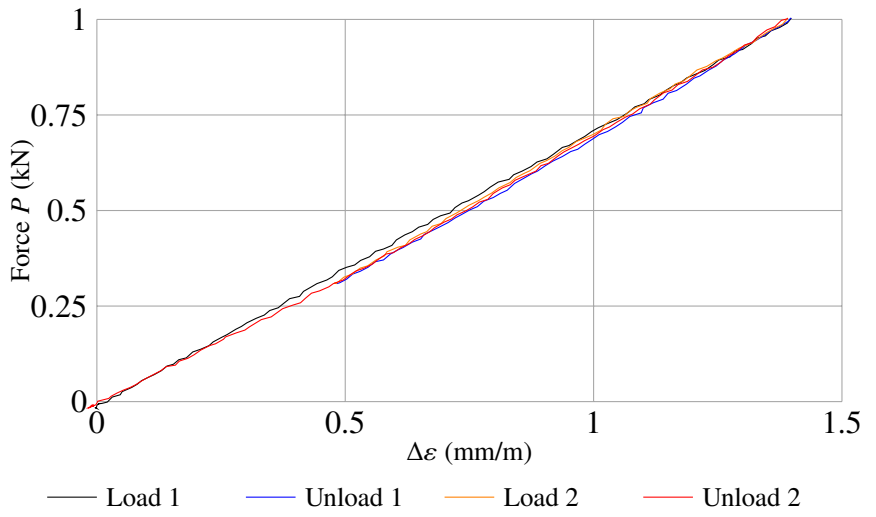

Figure 19: Applied force as function of relative deformation $\Delta \varepsilon$ 


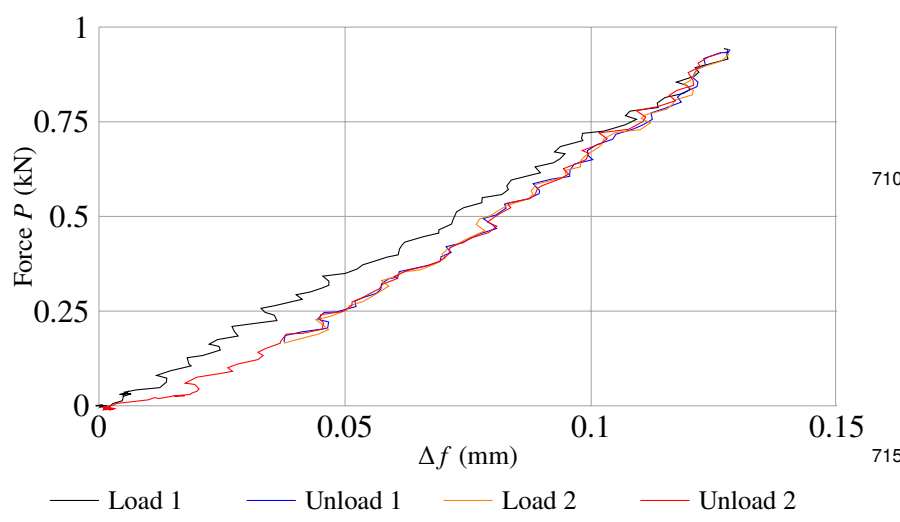

Figure 20: Applied force as function of relative deflection $\Delta f$

In contrast, the relative deflection $\Delta f$ (Figure 20) is noisier ${ }_{720}$ and still presents a slight non-linearity during reloading. Consequently, a linear regression is performed only for $P>0.5 \mathrm{kN}$. Furthermore, as noticed in Section 2.2, the stronger noise observed for $\Delta f$ is explained because $f_{A}$ and $f_{B}$ have comparable amplitudes $\left(\Delta f / f_{A} \sim 7 \%\right)$. $\mathrm{On}_{725}$ the contrary, the rotations $\varphi_{C}$ and $\varphi_{C^{\prime}}$ are of the same order of magnitude of the ratio between mid-span deflection $f_{A}$ and mid-span length $\frac{l}{2}:(\Delta \varphi l) /\left(2 f_{A}\right) \sim 230 \%$.

From these observations, we conclude that the linear regression must be achieved during the second loading ${ }_{730}$ phase and a careful attention has to be paid to the uniformity of the slope particularly for a low force $P$ and for the diagram of $P$ as a function of $\Delta f$. Moreover, the poor signal to noise ratio for $\Delta f$ is expected to yield inaccurate results. Finally, non negligible skew-symmetric deflec- ${ }_{735}$ tions related to wood variability are observed showing the rtance of two sensors on both sides of the experiment for each measurement.

\subsection{CFRP Young modulus determination}

In Table 3 the CFRP skins apparent Young modulus is given for each specimen. Recall that there are two sets 740 of CFRP skins used in this study (RS1 and RS2). Four specimen have been tested using the three methods of measurement (RS1-1, RS1-2, RS1-3, RS2-1).

Considering first the Young modulus values obtained from $\Delta \varphi$ and $\Delta \varepsilon$, it appears that the modulus derived from $_{75}$ $\Delta \varepsilon$. This was predicted by the FE simulation (Table 2) but seems more pronounced here. However, the relative difference between $E_{\mathrm{CFRP}}$ measured from each measurement remains less than $6 \%$ and is $4.4 \%$ in average. Even 750 if additional reproducibility test and more tests would be required, this agreement comforts the reliability of the measurement from rotation at supports. Hence only this data is retained for the rest of RS2 set.

Considering now the Young modulus derived from $\Delta f$, larger variations and much lower values are obtained. This was expected because of the poor signal to noise ratio of this measurement and makes the identification of the equivalent layer elastic shear modulus impossible from this data.

\subsection{Equivalent layer shear modulus $G_{C Z}$ determination}

The equivalent cross-layer shear modulus $G_{C Z}$ determined from the mid-span deflection and the three methods for deriving the bending modulus is presented in Table 4 . As expected, the values obtained from $\Delta f$ measurement are aberrant. In contrast, the values obtained from $\Delta \varphi$ and $\Delta \varepsilon$ are more in agreement with lower coefficients of variation. As more experiment were performed with $\Delta \varphi$, the averaged value of $G_{C Z}=124 \mathrm{MPa}$ with a coefficient of variation of $6.71 \%$ is now discussed in more details.

This value is in agreement with Voigt and Reuss bounds calculated in [16], assuming that the local elastic behavior of Norway spruce is the one obtained by Keunecke et al. [29]. Moreover, this value is larger than the equivalent rolling shear modulus measured by Franzoni et al. [11] on the same batch of wood. This is probably because narrow edges were glued in the present test whereas they were free in [11] as observed numerically by Perret et al. [16]. Finally, a lower coefficient of variation $(6.71 \%)$ is obtained compared to double-lap shear tests from Franzoni et al. [11] (27\%) on the same batch. This reduced variability obtained with this new methodology was expected since it is an average on several boards. It is closer to the actual variability of a CLT layer made of similar boards.

\section{Conclusion}

In this paper, we proposed a new methodology to identify experimentally the equivalent shear modulus at the layer scale by using bending test on sandwich structures. In this four-point bending, we advocate for a measure using inclinometers to identify the bending stiffness from the ends rotation, the estimation appears more reliable than with the classical estimation based on relative displacement at mid-span. This better accuracy is partly due to the averaging effect of rotation compared to the relative deflection between loading points. The measurement of rotation is also significantly less sensitive to the quality and the precision of sensors setup compared to the measurement of the variations of deflection. 


\begin{tabular}{cc|ccc}
\hline Specimen & CFRP & $\Delta f$ & $\Delta \varphi$ & $\Delta \varepsilon$ \\
\hline RS1-1 & Set 1 & 99.7 & 132 & 130 \\
RS1-2 & Set 1 & 115 & 131 & 123 \\
RS1-3 & Set 1 & 115 & 127 & 122 \\
RS2-1 & Set 2 & 97.2 & 110 & 104 \\
RS2-2 & Set 2 & - & 111 & - \\
RS2-3 & Set 2 & - & 117 & - \\
RS2-4 & Set 2 & - & 112 & - \\
RS2-5 & Set 2 & - & 112 & - \\
RS2-6 & Set 2 & - & 104 & - \\
RS2-7 & Set 2 & - & 96.8 & - \\
RS2-8 & Set 2 & - & 103 & - \\
RS2-9 & Set 2 & - & 101 & - \\
\hline Average & Set 1 (Set 2) & $110(97.2)$ & $130(106)$ & $125(104)$ \\
COV (\%) & Set 1 (Set 2) & $8.15(-)$ & $2.01(6.31)$ & $3.28(-)$ \\
Number & Set 1 (Set 2) & $3(1)$ & $3(9)$ & $3(1)$ \\
\hline
\end{tabular}

Table 3: CFRP longitudinal Young modulus (GPa) measured from $\Delta f, \Delta \varphi$ and $\Delta \varepsilon$

Then, we conducted a first experimental campaign on these sandwich structures which gives confidence in the

method even if larger and representative samples will be required to provide sound values. The equivalent cross-layer shear modulus of the sample was estimated as $124 \mathrm{MPa}{ }^{785}$ with a remarkably low coefficient of variation of $6.71 \%$. This is because, as a first approach in the present paper, the batch of wood was not statistically representative either of the species or of the various sawing patterns which may be 790 found in a single CLT panel. Without control of the sawing pattern and strength grades, sandwich beam samples should reflect the actual variability in practice. However, automated classification machines will possibly allow tor95 choose the sawing pattern and its orientation during CLT fabrication and refined strength class may be defined accordingly in the future. In this direction, the suggested testing procedure appears as a relevant scale for estimat-800 ing the actual variability of the equivalent layer elastic behavior in engineering practice.

Finally, we look forward to use this methodology to study the visco-elastic behavior of the equivalent cross-805 layer shear stiffness of timber which is needed for the long term design of Cross-Laminated-Timber. Currently, only few studies on the visco-elastic behavior of CrossLaminated-Timber panels have been published to the au- ${ }_{810}$ thors knowledge [48, 49, 50, 51]. In all these studies, the whole CLT panels are tested and the viscoelastic behavior of the cross-layer is not directly identified.

\section{References}

[1] I. Lomhlt, Stadthaus london: Murray grove building, 2015.

[2] J. Mairs, Anders berensson proposes wooden skyscraper with decorative facade for stockholm, 2016.

[3] M. French, Vienna plans world's tallest wooden skyscraper, 2015.

[4] K. Medlock, Construction of world's tallest building is underway in vancouver, 2016.

[5] C. European Committee for Standardisation, Eurocode 5-design of timber structures, 1993.

[6] C. Stora Enso, Document technique d'application 3/13-750 : Panneaux bois à usage structurel, Agrément Technique Européen (2014).

[7] H. Kreuzinger, Platten, scheiben und schalen: Ein berechnungsmodell für gängige statikprogramme, bauen mit holz 1 (1999) 34-39.

[8] K. Sab, A. Lebée, Homogenization of heterogeneous thin and thick plates, John Wiley \& Sons, 2015.

[9] L. Franzoni, A. Lebée, F. Lyon, G. Forêt, Influence of orientation and number of layers on the elastic response and failure modes on CLT floors: modeling and parameter studies, European Journal of Wood and Wood Products (2016).

[10] O. Perret, A. Lebée, C. Douthe, K. Sab, The bending-gradient theory for the linear buckling of thick plates: Application to cross laminated timber panels, International Journal of Solids and Structures 87 (2016) 139-152.

[11] L. Franzoni, A. Lebée, F. Lyon, G. Forêt, Elastic behavior of cross laminated timber and timber panels with regular gaps: Thick-plate modeling and experimental validation, Engineering Structures 141 (2017) 402-416.

[12] A. Thiel, G. Schickhofer, CLTdesigner-a software tool for designing cross-laminated-timber elements: 1d-plate-design, in: World conference on timber engineering, Italy.

[13] D. I. Jouravskii, Remarques sur la résistance d'un corps prismatique et d'une pièce composée en bois ou en tôle de fer à une force perpendiculaire à leur longueur, Annales des Ponts et Chaussées 12 (1856) 328-351. 


\begin{tabular}{c|ccc|lcl}
\hline Specimen & $\Delta f$ & $\Delta \varphi$ & $\Delta \varepsilon$ & & & \\
\hline RS1-1 & 412 & 131 & 137 & & & \\
RS1-2 & 185 & 131 & 152 & & & \\
RS1-3 & 171 & 131 & 145 & & & \\
RS2-1 & 154 & 110 & 128 & & & \\
RS2-2 & - & 129 & - & & & \\
RS2-3 & - & 118 & - & & & \\
RS2-4 & - & 120 & - & & & \\
RS2-5 & - & 110 & - & & & \\
RS2-6 & - & 135 & - & & & \\
RS2-7 & - & 124 & - & & & \\
RS2-8 & - & 126 & - & & & \\
RS2-9 & - & 122 & - & {$[11]$} & Upper bound [16] & Lower bound [16] \\
\hline Average & 231 & 124 & 140 & 110 & 125 & \\
COV (\%) & 52.9 & 6.71 & 7.41 & 27 & & \\
Number & 4 & 12 & 4 & 10 & & \\
\hline
\end{tabular}

Table 4: Equivalent layer rolling shear modulus $G_{C Z}(\mathrm{MPa})$ measured from $\Delta f, \Delta \varphi$ and $\Delta \varepsilon$

[14] S. Aicher, G. Dill-Langer, Basic considerations to rolling shear modulus in wooden boards, Otto-Graf-Journal 11 (2000) 157.

[15] S. Aicher, Z. Christian, M. Hirsch, Rolling shear modulus and355 strength of beech wood laminations, Holzforschung 70 (2016) 773-781.

[16] O. Perret, A. Lebée, C. Douthe, K. Sab, Equivalent layer stiffness of CLT: Closed-form bounds and numerical validation, (submitted) (2017).

[17] K. B. Dahl, K. Malo, Linear shear properties of spruce softwood, Wood science and technology 43 (2009) 499-525.

[18] F. F. P. Kollman, W. A. Côté, Principles of wood science and technology: solid wood, Allen \& Unwin, 1968.

[19] D. ASTM, Standard methods of testing small clear specimens865 of timber, Philadelphia (PA): American Society for Testing and Materials (1981).

[20] R. Youngs, The perpendicular-to-grain mechanical properties of red oak related to temperature, moisture content and time, Ph.D. thesis, 1957.

[21] J. Y. Liu, D. D. Flach, R. J. Ross, G. J. Lichtenberg, An improved shear test fixture using the losipescu specimen, ASME APPLIED MECHANICS DIVISION-PUBLICATIONS-AMD 231 (1998) 139-148.

[22] D. M. Moses, H. G. Prion, Anisotropic plasticity and the notched875 wood shear block, Forest products journal 52 (2002) 43.

[23] T. Ehrhart, R. Brandner, G. Schickhofer, A. Frangi, Rolling shear properties of some european timber species with focus on cross laminated timber (CLT): Test configuration and parameter study, in: Proceedings of the 2nd International Network on Timberso Engineering Research meeting, volume 48, pp. 61-78.

[24] N. Iosipescu, New accurate procedure for single shear testing of metals, J MATER 2 (1967) 537-566.

[25] J.-F. Dumail, K. Olofsson, L. Salmén, An analysis of rolling shear of spruce wood by the iosipescu method, Holzforschung885 54 (2000) 420-426.

[26] M. Arcan, Z. Hashin, , A. Voloshin, A method to produce uniform plane-stress states with applications to fiber-reinforced materials,
Experimental mechanics 18 (1978) 141-146.

[27] K. B. Dahl, K. Malo, Nonlinear shear properties of spruce softwood: experimental results, Wood science and technology 43 (2009) 539.

[28] U. Müller, A. Ringhofer, R. Brandner, G. Schickhofer, Homogeneous shear stress field of wood in an Arcan shear test configuration measured by means of electronic speckle pattern interferometry : description of the test setup, Wood science and technology 49 (2015) 1123-1136.

[29] D. Keunecke, W. Sonderegger, K. Pereteanu, T. Lüthi, P. Niemz, Determination of young's and shear moduli of common yew and norway spruce by means of ultrasonic waves, Wood science and technology 41 (2007) 309-327.

[30] R. Longo, D. Laux, S. Pagano, T. Delaunay, E. Le Clézio, O. Arnould, Elastic characterization of wood by Resonant Ultrasound Spectroscopy (RUS): a comprehensive study, Wood Science and Technology (2017).

[31] A. Jakobs, et al., Zur Berechnung von Brettlagenholz mit starrem und nachgiebigem Verbund unter plattenartiger Belastung mit besonderer Berücksichtigung des Rollschubes und der Drillweichheit, Ph.D. thesis, Universität der Bundeswehr München, Universitätsbibliothek, 2005.

[32] A. D2718, Standard test method for structural panels in planar shear (rolling shear), 2003.

[33] R. Görlacher, Ein verfahren zur ermittlung des rollschubmoduls von holz, European Journal of Wood and Wood Products 60 (2002) 317-322.

[34] G. Schickhofer, R. Brandner, H. Bauer, Introduction to CLT, product properties, strength classes, of COST Actions FP1402 \& FP1404 KTH Building Materials, 10.3. 2016 Cross Laminated Timber-A competitive wood product for visionary and fire safe buildings (2016) 9.

[35] P. Mestek, Punktgestützte Flächentragwerke aus Brettsperrholz (BSP): Schubbemessung unter Berücksichtigung von Schubverstärkungen, na, 2011.

[36] Q. Zhou, M. Gong, Y. H. Chui, M. Mohammad, Measurement of 
rolling shear modulus and strength of cross laminated timber fabricated with black spruce, Construction and Building Materials 64 (2014) 379-386.

[37] N.-E. 408, Timber structure-structural timber and glued laminated timber. determination of some physical and mechanical properties, 2012.

[38] H. Yoshihara, Y. Kubojima, K. Nagaoka, M. Ohta, Measurement of the shear modulus of wood by static bending tests, Journal of wood science 44 (1998) 15-20.

[39] H. Yoshihara, Y. Kubojima, Measurement of the shear modulus of wood by asymmetric four-point bending tests, Journal of wood science 48 (2002) 14-19.

[40] H. Yoshihara, T. Furushima, Shear strengths of wood measured by various short beam shear test methods, Wood science and technology 37 (2003) 189-197.

[41] R. Brandner, E. Gehri, T. Bogensperger, G. Schickhofer, Determination of modulus of shear and elasticity of glued laminated timber and related examinations, Cib W18 (2007) 40-12-12.

[42] R. Brandner, B. Freytag, G. Schickhofer, Determination of shear modulus by means of standardized four-point bending tests, $\mathrm{Cib}$ W18 (2008) 41-21-1.

[43] E. Gehri, Shear Problems in Timber Engineering - Analysis and Solutions, in: 11th World Conference on Timber EngineeringWorld Conference in Timber Engineering.

[44] K. Viverge, C. Boutin, F. Sallet, International Journal of Solids and Structures Model of highly contrasted plates versus experiments on laminated glass, International Journal of Solids and Structures 102-103 (2016) 238-258.

[45] A. Lebée, K. Sab, Homogenization of cellular sandwich panels, Comptes Rendus Mécanique 340 (2012) 320-337.

[46] H. G. Allen, Analysis and Design of Structural Sandwich Panels: The Commonwealth and International Library: Structures and Solid Body Mechanics Division, Elsevier, 2013.

[47] Hibbett, Karlsson, Sorensen, ABAQUS/standard: User's Manual, Part IV : Elements, volume 1, Hibbitt, Karlsson \& Sorensen, 1998.

[48] R. Jöbstl, G. Schickhofer, Comparative examination of creep of GLT - and CLT - slabs inbending, in: International Council for Research and Innovation in builduing and construction.

[49] C. Pirvu, E. Karacabeyli, Time-dependent behaviour of CLT, in: World Conference on Timber Engineering.

[50] F. Colling, Creep behavior of cross laminated timber in service class 2, Technical Report, Hochschule Augsburg, University of Applied Sciences, 2014.

[51] Y. Li, Duration-of-load and size effects on the rolling shear strength of cross laminated timber, Ph.D. thesis, University of British Columbia, 2015. 